Pacific Journal of Mathematics

EXISTENCE OF OSCILLATORY SOLUTIONS AND
ASYMPTOTIC BEHAVIOR FOR A CLASS OF THIRD ORDER LINEAR DIFFERENTIAL EQ U 


\section{EXISTENCE OF OSCILLATORY SOLUTIONS AND ASYMPTOTIC BEHAVIOR FOR A CLASS OF THIRD ORDER LINEAR DIFFERENTIAL EQUATIONS}

\section{ERBE}

Criteria are obtained for the existence of oscillatory solutions to the third order differential equation $y^{\prime \prime \prime}+p(t) y^{\prime \prime}+$ $q(t) y^{\prime}+r(t) y=0$. The asymptotic behavior of nonoscillatory solutions is also discussed, under the assumption that the equation has oscillatory solutions. Of primary concern are the cases when $p(t)$ does not change sign and $q(t) \leqq 0, r(t)>0$, for which fewer criteria exist.

1. Introduction. Concerning the coefficients of

$$
y^{\prime \prime \prime}+p(t) y^{\prime \prime}+q(t) y^{\prime}+r(t) y=0
$$

we assume $p^{\prime \prime}, q^{\prime}, r$ continuous real valued functions on $[a, \infty)$ and we are interested in establishing effective criteria for the existence of an oscillatory solution of (1.1) i.e., a solution which changes sign on each half-line $\left[t_{0},+\infty\right)$. We also discuss the asymptotic behavior of nonoscillatory solutions under the assumption that an oscillatory solution exists. Equation (1.1) is said to be oscillatory in case there exists at least one oscillatory solution; (1.1) is said to be disconjugate on $\left[t_{0},+\infty\right), t_{0} \geqq a$, in case no nontrivial solution of (1.1) has more than two zeros on $\left[t_{0},+\infty\right)$. Disconjugacy, oscillation, and nonoscillation for (1.1) have been extensively studied by numerous authors; we refer the reader to Barrett [1], Hanan [10], Lazer [17], Kim [16], Etgen and Shih [4], [5], [6], Jones [14], [15], and the references therein.

If $p(t) \equiv 0$ and $q(t) \equiv 0$, then the oscillatory behavior of (1.1) is much easier to determine and various well known integral and Kneser-type tests exist. For example, if $r(t) \geqq 0$ and $y^{\prime \prime \prime}+r(t) y=0$ is disconjugate, then ([10]) (see also [1], Lemma 2.6),

$$
\int^{\infty} \operatorname{tr}(t) d t<+\infty
$$

If, on the other hand,

$$
\int^{\infty} t^{2} r(t) d t<+\infty
$$


then $y^{\prime \prime \prime}+r(t) y=0$ is disconjugate ([9], see [1], p. 461). A corollary of a result of Lazer ([17], Theorem 3.1) implies that (1.1) is oscillatory in case

$$
\int^{\infty} t^{1+\delta} r(t) d t=+\infty, \quad \text { some } \quad 0<\delta<1
$$

Finally, comparison with the Euler equation shows that

$$
\limsup _{t \rightarrow \infty} t^{3} r(t)<\frac{2}{3 \sqrt{3}} \Rightarrow y^{\prime \prime \prime}+r(t) y=0 \quad \text { is disconjugate }
$$

and

$$
\liminf _{t \rightarrow \infty} t^{3} r(t)>\frac{2}{3 \sqrt{3}} \Rightarrow y^{\prime \prime \prime}+r(t) y=0 \quad \text { is oscillatory. }
$$

The above remarks hold also for the case $r(t) \leqq 0$ if $r(t)$ is replaced by $|r(t)|$ in (1.2)-(1.6) since $y^{\prime \prime \prime}+r(t) y=0$ is disconjugate iff its adjoint is disconjugate, provided $r(t)$ does not change sign (see [10], Theorem 4.7).

If $p(t) \equiv 0, q(t) \geqq 0, r(t)>0, t \geqq a$, then various criteria have been obtained for the existence or nonexistence of oscillatory solutions of (1.1) (see [17], Theorem 3.1 and [1], [5], [6], [7], [12], [16]). However, in the case $p(t) \equiv 0, q(t) \leqq 0, r(t)>0$, much less is known; the author is aware of only the result of Lazer ([17], Theorem 1.3) which shows that (1.1) is oscillatory if $p(t) \equiv 0, q(t) \leqq 0, r(t)>0$ and

$$
\int^{\infty}\left[r(t)-\frac{2}{3 \sqrt{3}}(-q(t))^{3 / 2}\right] d t=+\infty
$$

This result is sharp, in a certain sense, in that it is both necessary and sufficient if $q(t), r(t)$ are constants. We shall obtain below in $\$ 2$ criteria for the existence of oscillatory solutions for this class of equations when (1.7) may not hold (e.g., for the case when $r(t)$ is integrable). We actually shall consider the larger class of equations (1.1) in which $q(t) \leqq 0$, $r(t)>0$, and $p(t)$ does not change sign on $[a,+\infty)$. We shall relate the oscillatory behavior of (1.1) to the oscillatory behavior of a related third order equation of the form $y^{\prime \prime \prime}+R(t) y=0$ where $R(t) \geqq 0$ so that oscillation criteria of the type (1.4) or (1.6) may be applied. These criteria may then be extended by standard techniques to a class of equations which includes the case $p(t) \equiv 0, q(t) \leqq 0, r(t)<0$ and thereby supplement the criteria of Heidel [12] and Lazer [17].

In $\$ 3$ we generalize and extend results of Jones [15] and Lazer [17] which gives sufficient conditions under which nonoscillatory solutions of (1.1) tend to zero as $t$ tends to infinity, under the assumption that an oscillatory solution exists. 
Therefore, the oscillation criteria of $\$ 2$ are also sufficient conditions which guarantee that all nonoscillatory solutions tend to zero (with perhaps mild additional assumptions on the coefficients).

2. We begin with several results which will be needed subsequently.

LEMma 2.1. ([2]). Equation (1.1) is disconjugate on the interval I iff there exists $\alpha, \beta \in C^{2}(I)$ with $\alpha(t)<\beta(t)$ on $I$ and such that

$$
\begin{aligned}
& \alpha^{\prime \prime}(t)+f\left(t, \alpha(t), \alpha^{\prime}(t)\right) \geqq 0 \\
& \beta^{\prime \prime}(t)+f\left(t, \beta(t), \beta^{\prime}(t)\right) \leqq 0
\end{aligned}
$$

where $f\left(t, u, u^{\prime}\right)=3 u u^{\prime}+p(t) u^{\prime}+u^{3}+p(t) u^{2}+q(t) u+r(t)$.

A proof of this result may be found in [2], for example. Functions $\alpha(t), \beta(t)$ as in Lemma 2.1 are called lower and upper solutions, respectively, of the Riccati equation corresponding to (1.1).

The next two results are elementary generalizations of results of Lazer [17]; for completeness, we include the proofs.

LEMMA 2.2. If $q(t) \leqq 0, r(t)>0$ and $y(t) \not \equiv 0$ is a solution of (1.1) with $y(t) \geqq 0$ or $y(t) \leqq 0$ eventually, then there exists $c \in[a,+\infty)$ such that either

$$
y(t) y^{\prime}(t) \leqq 0, \quad t \geqq c
$$

or

$$
y(t) y^{\prime}(t) \geqq 0, \quad t \geqq c, \quad \text { and } \quad y(t)>0 \quad \text { for } \quad t \geqq c .
$$

Furthermore, if (2.1) holds, then

$$
\begin{gathered}
y(t) y^{\prime}(t) y^{\prime \prime}(t) \neq 0, \quad \operatorname{sgn} y(t)=\operatorname{sgn} y^{\prime \prime}(t) \neq \operatorname{sgn} y^{\prime}(t), \quad t \geqq a \quad \text { and } \\
\lim _{t \rightarrow \infty} y^{\prime}(t)=\lim _{t \rightarrow \infty} y^{\prime \prime}(t)=0, \quad \lim _{t \rightarrow \infty} y(t)=k \neq \pm \infty .
\end{gathered}
$$

Proof. To be specific, assume $y(t) \geqq 0$. We show first that $y(t)>0$ eventually. If not, choose consecutive double zeros $t_{1}<t_{2}$ so that $y(t)>0$ on $\left(t_{1}, t_{2}\right)$ and let $t_{3} \in\left(t_{1}, t_{2}\right)$ be such that $y^{\prime \prime}\left(t_{3}\right)=0$ and $y^{\prime \prime}(t)>0 \quad y^{\prime}(t)<0$ on $\left(t_{3}, t_{2}\right)$. Then the function

$$
w(t)=y(t) y^{\prime}(t) y^{\prime \prime}(t) P(t)
$$


satisfies $w^{\prime}(t)>0$ on $\left(t_{3}, t_{2}\right)$, where $P(t)=\exp \left(\int_{t_{3}}^{t} p d s\right)$. Since $w\left(t_{3}\right)=$ $w\left(t_{2}\right)=0$, we have a contradiction. Therefore $y(t)>0$ for all large $t$. We observe next that $y^{\prime}(t)$ can change sign at most two times. For if $y^{\prime}\left(t_{1}\right)=y^{\prime}\left(t_{2}\right)=0$ then it follows that $y^{\prime}(t)>0$ on $\left(t_{1}, t_{2}\right)$. Otherwise, if $y^{\prime}(t)<0$ on $\left(t_{1}, t_{2}\right)$, then $v(t)=-y^{\prime}(t)>0$ satisfies $v^{\prime \prime}+p v^{\prime}+q v \geqq 0$ on $\left(t_{1}, t_{2}\right)$ and this implies the existence of a solution $z(t)$ of $z^{\prime \prime}+p z^{\prime}+q z=0$ with $z\left(t_{1}\right)=z\left(t_{2}\right)=0$ and $0<v(t) \leqq z(t)$ on $\left(t_{1}, t_{2}\right)$ (cf. [13]). But this contradicts the fact that $z^{\prime \prime}+p z^{\prime}+q z=0$ is disconjugate (i.e., $q(t) \leqq 0$, cf. [11]). Hence, either $y^{\prime}(t) \geqq 0$ or $y^{\prime}(t)<0$ for all large $t$. In the latter case, since $\left(P y^{\prime \prime}\right)^{\prime}=-P q y^{\prime}-P r y<0$, we see that the function $w=$ $y y^{\prime} y^{\prime \prime} P$ satisfies $w^{\prime}>0$ on any interval on which $y^{\prime \prime}>0$. Since $y^{\prime \prime} \leqq 0$ cannot hold for all large $t$, it follows that $y^{\prime \prime}(t)>0$ for all large $t$, say $t \geqq T$. Furthermore, in this case, one can show as in the first part of the proof that $w(t) \neq 0$ for $a \leqq t<T$. The fact that $y^{\prime}(t) \rightarrow 0$ and $y^{\prime \prime}(t) \rightarrow 0$ is clear. This completes the proof.

LEMmA 2.3. Let $q(t) \leqq 0, r(t)>0$. A necessary and sufficient condition for (1.1) to have oscillatory solutions is that for any nontrivial nonoscillatory solution (2.3) and (2.4) hold.

Proof. Clearly, if (2.3) and (2.4) hold for any nontrivial nonoscillatory solution, then any solution which vanishes once is oscillatory. Now if $y(t)$ is a nontrivial nonoscillatory solution for which (2.3) and (2.4) do not hold, then $y(t)$ satisfies (2.2). Hence, with $u(t)=y^{\prime}(t) / y(t), t \geqq c$, we find that the functions $\alpha(t) \equiv 0$ and $\beta(t) \equiv u(t)$ satisfy the hypotheses of Lemma 2.1. (Since solutions to initial value problems for the Riccati equation are unique and since $r(t)>0$, it follows that $u(t)>0, t>c$.) This completes the proof.

REMARK. If $q(t) \leqq 0, r(t)>0$, there will always exist a solution of (1.1) satisfying (2.3), (2.4). This follows either from an easy generalization of a result of Lazer ([17], Theorem 1.1) or by a result of Hartman and Wintner (see [10], p. 510).

We may now state and prove our first existence theorem for oscillatory solutions of (1.1).

THEOREM 2.4. Let $p(t) \leqq 0, q(t) \leqq 0, r(t)>0, q(t)-p^{\prime}(t) \leqq 0$ and $2 r(t)-q^{\prime}(t)+p^{\prime \prime}(t) \geqq 0$. Assume further that for each $\lambda>0$ there exists $t_{\lambda} \geqq a$ such that $t \geqq t_{\lambda}$ implies

$$
Q(t, \lambda) \geqq 0
$$


where $Q(t, \lambda)=r(t)+\lambda q(t)+\frac{1}{2} p(t)\left(\lambda^{2}-2 \lambda p(t)-q(t)+p^{\prime}(t)\right)$ and such that the equation

$$
y^{\prime \prime \prime}+Q(t, \lambda) y=0
$$

is oscillatory. Finally assume

$$
\begin{aligned}
\int^{\infty}\left(q-p^{\prime}-p^{2}\right) d t & >-\infty \\
\int^{\infty} t^{2}\left(2 r(t)-q^{\prime}(t)+p^{\prime \prime}(t)\right) d t & =+\infty .
\end{aligned}
$$

Then (1.1) has an oscillatory solution.

Proof. If not, then (2.2) holds for some nonoscillatory solution $y(t)$, which we assume satisfies $y(t)>0, y^{\prime}(t) \geqq 0, t \geqq c$. If we define the energy function

$$
G(y(t))=2 y y^{\prime \prime}+2 y y^{\prime} p+\left(q-p^{\prime}\right) y^{2}-y^{\prime 2}
$$

then a calculation shows

$$
G^{\prime}(y(t))=2 y^{\prime 2} p+\left(q^{\prime}-p^{\prime \prime}-2 r\right) y^{2} \leqq 0, \quad t \geqq c .
$$

We consider three cases:

(i) Suppose $y^{\prime \prime}(t)$ has arbitrarily large zeros at $t_{n} \rightarrow+\infty$. Then $G\left(y\left(t_{1}\right)\right) \leqq 0$ and with $u=y^{\prime} / y$, we have

$$
\begin{aligned}
2 y^{2} u^{\prime}=2 y y^{\prime \prime}-2 y^{\prime 2} & =G(y(t))-y^{\prime 2}-2 y y^{\prime} p-\left(q-p^{\prime}\right) y^{2} \\
& \leqq-y^{\prime 2}-2 y y^{\prime} p-\left(q-p^{\prime}\right) y^{2}, \quad t \geqq t_{1} .
\end{aligned}
$$

Thus,

$$
u^{\prime}+p u+\frac{1}{2} u^{2}+\frac{1}{2}\left(q-p^{\prime}\right) \leqq 0
$$

which implies

$$
u^{\prime}+\frac{1}{2}\left(q-p^{\prime}-p^{2}\right) \leqq 0, \quad t \geqq t_{1} .
$$

Since $\int^{\infty}\left(q-p^{\prime}-p^{2}\right) d t>-\infty,(2.10)$ implies that $u(t) \leqq \lambda, t \geqq t_{1}$ for some $\lambda>0$. Now rewriting (1.1) as

$$
\left(P y^{\prime \prime}\right)^{\prime}+P q y^{\prime}+P r y=0, \quad P=\exp \int_{t_{1}}^{t} p d s
$$


we obtain

$$
\left(P y^{\prime \prime}\right)^{\prime}+P(r+\lambda q) y \leqq 0, \quad t \geqq t_{1} .
$$

Let $t_{n} \geqq t_{\lambda}$. Integrating (2.12) between $t_{n}$ and $t_{n+k}$ and taking the limit as $k \rightarrow \infty$ we get

$$
\int_{t_{n}}^{\infty} P(t)(r(t)+\lambda q(t)) y(t) \leqq 0 .
$$

This contradicts the fact that $r(t)+\lambda q(t)>0$ for $t \geqq t_{\lambda}$.

(ii) Next, suppose $y(t)>0, y^{\prime}(t)>0, y^{\prime \prime}(t)>0, t \geqq t_{0} \geqq a$. In this case, since $y(t) \geqq m t$ for $m>0$ sufficiently small, we have from (2.7) and (2.8)

$$
G(y(t))=G\left(y\left(t_{0}\right)\right)+\int_{t_{0}}^{t}\left(2 y^{\prime 2} p+\left(q^{\prime}-p^{\prime \prime}-2 r\right) y^{2}\right) d s
$$

and therefore $G(y(t)) \rightarrow-\infty$ by (2.6). Therefore, as in part (i), we have $u(t) \leqq \lambda, t \leqq t_{0}$, for some $\lambda>0$. Also, from (2.9) we get

$$
p u^{\prime} \geqq-p^{2} u-\frac{1}{2} p u^{2}-\frac{1}{2} p\left(q-p^{\prime}\right)
$$

so that

$$
p\left(u^{\prime}+u^{2}\right) \geqq \frac{1}{2} p\left(\lambda^{2}-2 p \lambda-q+p^{\prime}\right) .
$$

Hence, from (2.15) we have in the Riccati equation corresponding to (1.1),

$$
u^{\prime \prime}+3 u u^{\prime}+u^{3}+Q(t, \lambda) \leqq 0, \quad t \geqq t_{1} .
$$

Since $u(t)>0 \quad t \geqq t_{1}$ and since $Q(t, \lambda) \geqq 0, t \geqq t_{\lambda}$, equation (2.5) is disconjugate on $\left[t_{\lambda}, \infty\right)$ by Lemma 2.1, a contradiction.

(iii) Finally, suppose $y(t)>0, y^{\prime}(t)>0, y^{\prime \prime}(t)<0, t \geqq t_{0}$. In this case, $u=y^{\prime} / y$ satisfies $u^{\prime}+u^{2}<0, t \geqq t_{0}$ so that $0<u(t) \leqq \lambda, t \geqq t_{0}$ and hence

$$
u^{\prime \prime}+2 u u^{\prime}+u^{3}+\lambda q+r \leqq 0, \quad t \geqq t_{0}
$$

But since $\lambda q(t)+r(t) \geqq Q(t, \lambda) \geqq 0, t \geqq t_{\lambda}$, it follows ([10]) that

$$
y^{\prime \prime \prime}+(\lambda q(t)+r(t)) y=0
$$

is oscillatory, a contradiction to (2.17) by Lemma 2.1 . 
Therefore, we conclude that (1.1) has an oscillatory solution.

With slightly different hypotheses, one may obtain an additional criterion for the existence of oscillatory solutions which may be easier to check than that of Theorem 2.4.

THEOREM 2.5. Let $p(t) \leqq 0, q(t) \leqq 0, r(t)>0, q(t)-p^{\prime}(t) \leqq 0$, and $2 r(t)-q^{\prime}(t)+p^{\prime \prime}(t) \geqq 0$. Assume further that for each $\lambda>0$ there exists $t_{\lambda} \geqq a$ such that $t \geqq t_{\lambda}$ implies $r(t)+\lambda(q(t)+p(t)) \geqq 0$ and such that the equation

$$
y^{\prime \prime \prime}+(\lambda(q(t)+p(t))+r(t)) y=0
$$

is oscillatory. Finally assume that $|p(t)|<K$ and $\left|q(t)-p^{\prime}(t)\right|<K$ for some $K>0$ and that (2.6) holds. Then (1.1) has an oscillatory solution.

Proof. We argue as in Theorem 2.4. The proof there shows that cases (i) and (iii) cannot occur. So suppose case (ii) holds and let $y(t)>0, y^{\prime}(t)>0, y^{\prime \prime}(t)>0, t \geqq t_{0} \geqq a$.

We obtain again that $u(t) \leqq \lambda, t \geqq t_{1}$, for some $\lambda>0$. Then from (2.9) and the boundedness of $|p(t)|$ and $\left|q(t)-p^{\prime}(t)\right|$ it follows that $u^{\prime}$ is bounded above and hence instead of (2.15) we obtain

$$
p\left(u^{\prime}+u^{2}\right) \geqq \mu p
$$

for some $\mu \geqq \lambda$. Therefore, in the Riccati equation corresponding to (1.1) we obtain

$$
u^{\prime \prime}+3 u u^{\prime}+u^{3}+\mu(p+q)+r(t) \leqq 0
$$

so that equation (2.19) is disconjugate by Lemma 1.1, a contradiction. This proves the theorem.

The next result gives an oscillation criterion for the case when $p(t) \geqq 0, q(t) \leqq 0, r(t)>0$.

THEOREM 2.6. Let $\quad p(t) \geqq 0, \quad q(t) \leqq 0, \quad r(t)>0, \quad 2 r(t)-$ $q^{\prime}(t)-p(t) q(t) \geqq 0$ and assume for each $\lambda>0$ there exists $t_{\lambda} \geqq a$ such that $r(t)+\lambda q(t) \geqq 0, t \geqq t_{\lambda}$, and such that the equation

$$
y^{\prime \prime \prime}+(r+\lambda q) y=0
$$

is oscillatory. Assume further that

$$
\left|\int_{a}^{\infty} q d t\right|+\int_{a}^{\infty} p d t<+\infty
$$


and

$$
\int_{a}^{\infty} t^{2}\left(2 r-p q-q^{\prime}\right) d t=+\infty
$$

Then (1.1) has an oscillatory solution.

Proof. We proceed as in the proofs of the two previous theorems. Assume therefore that $y(t)$ is a nonoscillatory solution of (1.1) with $y(t)>0, y^{\prime}(t) \geqq 0, t \geqq c \geqq a$. We define

$$
H(y(t))=P(t)\left(2 y^{\prime \prime} y-y^{\prime 2}+q y^{2}\right), \quad P(t)=\exp \left(\int_{c}^{t} p d s\right)
$$

and a calculation shows that $H(y(t))$ is nonincreasing and

$$
H(y(t))=H\left(y\left(t_{0}\right)\right)+\int_{t_{0}}^{t} P(s)\left\{y^{2}\left(p q+q^{\prime}-2 r\right)-p y^{\prime 2}\right\} d s .
$$

We again consider three cases:

(i) If $y^{\prime \prime}\left(t_{n}\right)=0, t_{n} \rightarrow+\infty$, then since $H\left(y\left(t_{1}\right)\right) \leqq 0$ we have

$$
2 u^{\prime}(t) \leqq-(u(t))^{2}-q(t)<-q(t), \quad t \geqq t_{1}
$$

so that $u(t) \leqq \lambda$ for some $\lambda>0$ by (2.23), and the proof proceeds as in Theorem 2.4 to obtain a contradiction.

(ii) 'If $y(t)>0, y^{\prime}(t)>0, y^{\prime \prime}(t)>0, t \geqq c \geqq a$, then by (2.26) and (2.24) we see that $H(y(t)) \rightarrow-\infty$ and hence $u(t) \leqq \lambda$ for some $\lambda>0$ as in case (i) above. Therefore, from (1.1) and $p y^{\prime \prime} \geqq 0$, we obtain

$$
y^{\prime \prime \prime}+(\lambda q+r) y \leqq 0, \quad t \leqq t_{\lambda}
$$

But (2.28) implies (with $u=y^{\prime} / y$ ) that equation (2.21) is disconjugate by Lemma 2.1, a contradiction.

(iii) If $y(t)>0, y^{\prime}(t)>0, y^{\prime \prime}(t)<0, t \geqq c \geqq a$, then clearly $u(t) \leqq \lambda$ for some $\lambda>0, t \geqq c$, and this implies that (2.12) holds. Therefore,

$$
\left(P(t) y^{\prime \prime}(t)\right)^{\prime} \leqq 0, \quad t \geqq c
$$

so that

$$
y^{\prime \prime}(t) \leqq P^{-1}(t) P\left(t_{1}\right) y^{\prime \prime}\left(t_{1}\right) \leqq k P\left(t_{1}\right) y^{\prime \prime}\left(t_{1}\right)<0, \quad t \geqq t_{1}
$$

where

$$
k=\lim _{t \rightarrow \infty} P^{-1}(t)>0
$$


Integrating (2.30) shows that $y^{\prime}(t) \rightarrow-\infty$, a contradiction. This completes the proof of the theorem.

In ([3], Theorem 4.2) it was shown that if $p(t) \leqq 0,2 r-q^{\prime}+p^{\prime \prime}>0$ $\left(p \geqq 0,2 r-q^{\prime}+p^{\prime \prime}<0\right)$ then equation (1.1) is of class $C_{I}\left(C_{I I}\right)$, generalizing a result of Hanan ([10], Theorem 2.2). (Recall that (1.1) is said to be of class $C_{I}\left(C_{I I}\right)([10])$ if no nontrivial solution of (1.1) satisfies $y\left(t_{0}\right)=y\left(t_{1}\right)=$ $y^{\prime}\left(t_{1}\right)=0\left(y\left(t_{0}\right)=y^{\prime}\left(t_{0}\right)=y\left(t_{1}\right)=0\right)$ for any $a \leqq t_{0}<t_{1}<+\infty$.) Furthermore, it was shown in [10], that if (1.1) is of class $C_{I}\left(C_{I I}\right)$ then it is oscillatory iff its adjoint is oscillatory. In view of these results one may easily obtain criteria for the existence of oscillatory solutions for the case where $p(t)$ does not change sign and $q(t) \leqq 0, r(t)<0$. We state the following two results, which are corollaries of Theorems 2.4 and 2.6, respectively. In both, the adjoint equation of (1.1) satisfies the hypothesis of Theorem 2.4 or 2.6. Similar results may be obtained from Theorem 2.5 and we leave the statement of these to the interested reader.

COROLlaRy 2.7. Let $p(t) \geqq 0, q(t) \leqq 0, r(t)<0, q(t)-2 p^{\prime}(r) \leqq 0$, $q^{\prime}(t)-p^{\prime \prime}(t)-r(t)>0$ and assume for each $\lambda>0$ there exists $t_{\lambda}$ such that $t \geqq t_{\lambda}$ implies $R(t, \lambda) \geqq 0$, where

$$
R(t, \lambda)=q^{\prime}-p^{\prime \prime}-r+\lambda\left(q-2 p^{\prime}\right)-\frac{1}{2} p\left(\lambda^{2}+2 \lambda p-q+p^{\prime}\right)
$$

and such that $y^{\prime \prime \prime}+R(t, \lambda) y=0$ is oscillatory. Assume further that $\int_{a}^{\infty}\left(q-p^{\prime}-p^{2}\right) d t>-\infty$ and $\int_{a}^{\infty} t^{2}\left(q^{\prime}-p^{\prime \prime}-2 r\right) d t=+\infty$. Then (1.1) has an oscillatory solution.

COROLlaRy 2.8. Let $p \leqq 0, q \leqq 0, r<0, q-2 p^{\prime} \leqq 0, q^{\prime}-p^{\prime \prime}-r>$ 0 and $q^{\prime}-2 r+p\left(q-2 p^{\prime}\right) \geqq 0$. Assume for each $\lambda>0$ there exists $t_{\lambda}$ such that $t \geqq t_{\lambda}$ implies

$$
S(t, \lambda) \equiv q^{\prime}-p^{\prime \prime}-r+\lambda\left(q-2 p^{\prime}\right) \geqq 0,
$$

and such that $y^{\prime \prime \prime}+S(t, \lambda) y=0$ is oscillatory. Assume further that

$$
\left|\int_{a}^{\infty}\left(q-2 p^{\prime}\right) d t\right|+\left|\int_{a}^{\infty} p d t\right|<+\infty
$$

and

$$
\int_{a}^{\infty} t^{2}\left(q^{\prime}-2 r+p\left(q-2 p^{\prime}\right)\right) d t=+\infty
$$

Then (1.1) has an oscillatory solution. 
REMARK. It is interesting to compare the previous results with known disconjugacy criteria. For example, if $p(t) \leqq 0, q(t) \leqq 0, r(t)>0$, $q-p^{\prime} \leqq 0$, and $r-q^{\prime}+p^{\prime \prime} \leqq 0$, then equation (1.1) is disconjugate ([5], Theorem 1). It is therefore easy to give an example of equation (1.1) which is disconjugate but which satisfies all of the hypotheses of Theorem 2.4 or 2.5 except for the assumption that equation (2.5) or (2.19) is oscillatory. This indicates sharpness, in a certain sense. As an example of a class of equations which possess oscillatory solutions but for which known oscillation criteria fail, let

$$
p(t)=-k t^{\alpha}, \quad q(t)=-m t^{\beta}, \quad k_{1} t^{\delta_{1}} \leqq r(t) \leqq k_{2} t^{\delta_{2}}
$$

where $m, k_{1}, k_{2}$ are $>0, k \geqq 0$, and

$$
-3 \leqq \delta_{1} \leqq \delta_{2}<-1, \quad \alpha, \beta<\delta_{1}, \quad \text { and } \quad k_{1}>\frac{2}{3 \sqrt{3}} \quad \text { if } \quad \delta_{1}=-3
$$

Then all hypotheses of Theorem 2.5 hold. Equation (2.19) is oscillatory by comparison with the Euler equation (see (1.6)). Since $\int_{a}^{\infty} r(t) d t<+\infty$, the criterion of Lazer does not apply. Similar examples may be given using integral criteria of the type (1.4). As an example using Corollary 2.7 or 2.8 for the case $p(t) \equiv 0$, consider $q(t)=-m t^{\gamma}, r(t)=-k t^{\delta}$, where $m, k>0, \delta \geqq-3, \gamma<-1, \gamma<\delta$. Then it is easily verified that all of the hypotheses of Corollary 2.7 or 2.8 hold. (Here if $\delta=-3$, we need $k>2 / 3 \sqrt{3}$.) Again this oscillatory behavior may not be obtained from the criterion of Lazer ([17], Theorem 2.6) or from the result of Heidel ([12], Corollary 2.9), if for example $\gamma>-2$.

3. In this section we discuss the behavior of the nonoscillatory solutions of (1.1) under the assumption that (1.1) is oscillatory. We begin with a slight generalization of a result of Lazer ([17], Theorem 3.4; see also [10], [12]). In these first few results, no assumption on the sign of $q(t)$ is made.

LEMMA 3.1. If $r(t)>0$ and the equation

$$
y^{\prime \prime}+\left(q-\frac{p^{\prime}}{2}\right) y=0
$$

is disconjugate and if equation (1.1) has an oscillatory solution, then any nonoscillatory solution $y(t)$ of (1.1) satisfies $y(t) y^{\prime}(t)<0$ eventually.

Proof. Suppose $y>0, t \geqq T$ and assume $t_{1}<t_{2}$ are consecutive 
zeros of $y^{\prime}, t_{1} \geqq T$. Then multiplying (1.1) by $y^{\prime}$ and integrating by parts between $t_{1}$ and $t_{2}$ gives

$$
\int_{t_{1}}^{t_{2}} r y y^{\prime}=\int_{t_{1}}^{t_{2}}\left(y^{\prime \prime}\right)^{2} d t-\int_{t_{1}}^{t_{2}}\left(q-\frac{p^{\prime}}{2}\right)\left(y^{\prime}\right)^{2} d t .
$$

Now the right hand side of (3.2) is positive as one notes by expanding $\int_{t_{1}}^{t_{2}}\left(y^{\prime \prime}-y^{\prime} v^{\prime} / v\right)^{2} d t>0$, where $v$ is a solution of (3.1) with $v\left(t_{1}\right)=0$, $v^{\prime}\left(t_{1}\right)>0, v>0$ on $\left(t_{1},+\infty\right)$. Hence, it follows that $y^{\prime}>0$ between consecutive zeros. But this means that $u=y^{\prime} / y$ satisfies $u \geqq 0, t \geqq t_{1}$, therefore $u\left(t_{2}\right)=u^{\prime}\left(t_{2}\right)=0$. Since solutions of initial value problems for the Riccati equation are unique, we would have $u \equiv 0$, a contradiction. Thus, it follows that $y^{\prime}>0$ or $y^{\prime}<0, t \geqq t_{1}$. If $y^{\prime}>0$, then $u>0, t \geqq t_{1}$ and now with $\alpha \equiv 0, \beta=u(t)$, we find that (1.1) is disconjugate by Lemma 2.1. Therefore, $y^{\prime}<0, t \geqq t_{1}$.

REMARK. Nonoscillatory solutions satisfying the conclusion of Lemma 3.1 exist (cf. [3]).

THEOREM 3.2. Let the hypotheses of Lemma 3.1 hold and, in addition, assume that $q-p^{\prime} \leqq 0, p \leqq 0, p^{\prime} \geqq 0$ and that there exists $M>0$ with $\operatorname{tp}(t)>-M$ and $t^{2} q(t)<M$. Finally, let

$$
\liminf _{t \rightarrow \infty} t^{3} r(t)>0
$$

or

$$
\liminf _{t \rightarrow \infty}\left(t p(t)-t^{2} q(t)\right)>2 .
$$

Then every nonoscillatory solution $y(t)$ of (1.1) satisfies

$$
\lim _{t \rightarrow \infty} y(t)=\lim _{t \rightarrow \infty} y^{\prime}(t)=\lim _{t \rightarrow \infty} y^{\prime \prime}(t)=0 \text {. }
$$

Proof. Suppose $y(t)$ is a nonoscillatory solution which does not tend to zero, $y(t)>0$. From Lemma 1.1, $y(t) \rightarrow c>0$ and $y^{\prime}(t)<0$, $t \geqq T$. Since $y^{\prime \prime}(t) \leqq 0$ cannot hold for all large $t$, suppose there exist $t_{1}<t_{2}$ with $y^{\prime \prime}\left(t_{1}\right)=y^{\prime \prime}\left(t_{2}\right)=0, y^{\prime \prime}>0$ on $\left(t_{1}, t_{2}\right), T \leqq t_{1}$. Then an integration of (1.1) yields

$$
p\left(t_{2}\right) y^{\prime}\left(t_{2}\right)-p\left(t_{1}\right) y^{\prime}\left(t_{1}\right)+\int_{t_{1}}^{t_{2}}\left(q-p^{\prime}\right) y^{\prime} d t+\int_{t_{1}}^{t_{2}} r y d t=0
$$

and since the sum of the two integrals is positive, (3.6) implies $p\left(t_{2}\right)<$ 
$p\left(t_{1}\right)$, a contradiction. Therefore, it follows that $y^{\prime \prime}>0$ for all large $t$, say $t \geqq T$. Then from the Mean Value Theorem and the fact that $y(t) \rightarrow c$ $>0$, we find that given $\delta>0$ there exists $t_{0}=t_{0}(\delta) \geqq T$ with

$$
u(t)=\frac{y^{\prime}(t)}{y(t)}>\frac{-\delta}{t-t_{0}}, \quad t>t_{0}
$$

With $s=t-t_{0}$ and $\alpha(t)=-\delta s^{-1}$ a calculation shows that

$$
\begin{aligned}
\alpha^{\prime \prime}+ & 3 \alpha \alpha^{\prime}+p \alpha^{\prime}+\alpha^{3}+p \alpha^{2}+q \alpha+r \\
= & -s^{-3}\left(\delta^{3}+3 \delta^{2}+2 \delta\right)+s^{-2} p(t)\left(\delta+\delta^{2}\right) \\
& -s^{-1} \delta q(t)+r(t) .
\end{aligned}
$$

One can now verify that (3.3) or (3.4) implies that the right hand side of (3.8) is nonnegative for sufficiently small $\delta>0$. Therefore, by Lemma 2.1, equation (1.1) is disconjugate, a contradiction. This proves the theorem.

REMARK. The assumptions $q-p^{\prime} \leqq 0, p \leqq 0, p^{\prime} \geqq 0$ in the previous theorem can be replaced by the assumption that $q-p^{\prime}$ is bounded below, $t^{-1} p(t)$ is bounded above and $\int^{\infty}\left(r-q^{\prime}+p^{\prime \prime}\right) d t=+\infty$. It then follows from (3.6) by a routine integration by parts that $y^{\prime \prime}>0$ for all large $t$. Of course, if $q(t) \leqq 0$, then any nonoscillatory solution of (1.1) satisfies (2.3), (2.4). Hence, one needs only $t p(t)-t^{2} q(t)$ bounded below and either (3.3) or (3.4) holding to conclude (3.5) holds if (1.1) is oscillatory.

Now suppose that $y(t)$ is a solution of (1.1) with $y>0, y^{\prime}<0, y^{\prime \prime}>0$, $t \geqq T$, and assume also that $u(t), v(t)$ are linearly independent oscillatory solutions of (1.1), and let $W(t), W_{1}(t), W_{2}(t)$ denote the Wronskians of the triple $y, u, v$, the pair $y, u$ and the pair $y, v$, respectively. Then $W_{1}(t)$ and $W_{2}(t)$ are linearly independent oscillatory solutions of the adjoint equation of (1.1) ([1])

$$
y^{\prime \prime \prime}-p y^{\prime \prime}+\left(q-2 p^{\prime}\right) y^{\prime}+\left(q^{\prime}-p^{\prime \prime}-r\right) y=0
$$

and are also solutions of the second order equation

$$
\left|\begin{array}{lll}
W_{1} & W_{2} & z \\
W_{1}^{\prime} & W_{2}^{\prime} & z^{\prime} \\
W_{1}^{\prime \prime} & W_{2}^{\prime \prime} & z^{\prime \prime}
\end{array}\right|=0 .
$$

Since $W(t)$ satisfies $W^{\prime}+p W=0$ we obtain 


$$
\begin{aligned}
& \text { (3.11) }\left|\begin{array}{ll}
W_{1} & W_{2} \\
W_{1}^{\prime} & W_{2}^{\prime}
\end{array}\right|=y(t) W(t)=k y(t) P^{-1}(t), \quad P(t)=\exp \int_{T}^{t} p d s \\
& k=W(T) \neq 0 \text {. }
\end{aligned}
$$

Therefore, differentiating (3.11) we get

$$
k\left(y^{\prime}-p y\right) P^{-1}(t)=\left|\begin{array}{cc}
W_{1} & W_{2} \\
W_{1}^{\prime \prime} & W_{2}^{\prime \prime}
\end{array}\right|
$$

and

(3.13) $k\left(y^{\prime \prime}-2 p y^{\prime}-p^{\prime} y+p^{2} y\right) P^{-1}(t)=\left|\begin{array}{ll}W_{1}^{\prime} & W_{2}^{\prime} \\ W_{1}^{\prime \prime} & W_{2}^{\prime \prime}\end{array}\right|+\left|\begin{array}{cc}W_{1} & W_{2} \\ W_{1}^{\prime \prime \prime} & W_{2}^{\prime \prime \prime}\end{array}\right|$.

By (3.9) and (3.11) we have

$$
\left|\begin{array}{cc}
W_{1} & W_{2} \\
W_{1}^{\prime \prime \prime} & W_{2}^{\prime \prime \prime}
\end{array}\right|=k P^{-1}(t)\left(p y^{\prime}-p^{2} y-\left(q-2 p^{\prime}\right) y\right) .
$$

Therefore (3.10) is equivalent to

$$
y z^{\prime \prime}+z^{\prime}\left(p y-y^{\prime}\right)+z\left(y^{\prime \prime}-3 p y^{\prime}+\left(2 p^{2}+q-3 p^{\prime}\right) y\right)
$$

or

$$
\left(\theta(t) z^{\prime}\right)^{\prime}+\theta(t) h(t) z=0
$$$$
\theta(t)=P(t) y^{-1}(t), \quad h(t)=y^{-1}(t)\left(y^{\prime \prime}-3 p y^{\prime}+\left(2 p^{2}+q-3 p^{\prime}\right) y\right) .
$$

The change of variable $z(t)=t^{\frac{1}{2}} w(t)$ transforms (3.16) into

$$
\left(t \theta(t) w^{\prime}\right)^{\prime}+t \theta(t) f(t) w=0
$$

where

$$
f(t)=h(t)+\frac{1}{2 t}\left(p-\frac{y^{\prime}}{y}\right)-\frac{1}{4 t^{2}} .
$$

Now one can easily verify that if $y(t)>0, y^{\prime}(t)<0, y^{\prime \prime}(t)>0, t \geqq T$, then (cf. [15])

$$
\lim _{t \rightarrow \infty} t y^{\prime}(t)=0
$$

and

$$
\int^{\infty} t y^{\prime \prime}(t) d t<+\infty
$$


Therefore, if $\lim _{t \rightarrow \infty} y(t)=c>0$ and if

(3.20) $0<\delta \leqq P(t) \leqq M<+\infty$ for all $t$ and some $\delta, m>0$, and

$$
-3 p y^{\prime}+\left(2 p^{2}+q-3 p^{\prime}\right) y \leqq 0
$$

then (3.16) will be nonoscillatory by the Sturm Comparison Theorem, since (3.19) and (3.20) imply

$$
\left(\theta(t) z^{\prime}\right)^{\prime}+\theta(t) y^{-1}(t) y^{\prime \prime}(t) z=0
$$

is nonoscillatory ([11], [18]) and (3.21) is equivalent to $h(t) \leqq y^{\prime \prime} / y$.

If instead of (3.16) we use (3.17), and if

$$
y^{\prime \prime \prime}(t) \leqq 0, \quad t \geqq T
$$

holds, then ([15])

$$
\lim _{t \rightarrow \infty} t^{2} y^{\prime \prime}(t)=0
$$

Thus, if $\lim _{t \rightarrow \infty} y(t)=c>0$ and

$$
\limsup _{t \rightarrow \infty} t^{2} f(t)<0
$$

then (3.17)' will be nonoscillatory.

In this case, (3.25) is equivalent to

$$
\limsup _{t \rightarrow \infty}\left(-3 p t^{2} \frac{y^{\prime}}{y}+t^{2}\left(2 p^{2}+q-3 p^{\prime}\right)+\frac{1}{2} t p\right)<\frac{1}{4} \text {. }
$$

We collect the above remarks in the following

THEOREM 3.3. Let (1.1) have a 2-dimensional subspace of oscillatory solutions and let $y(t)$ be a nonoscillatory solution of (1.1) with $y(t)>0, y^{\prime}(t)<0, y^{\prime \prime}(t)>0, t \geqq T$. Then

$$
\lim _{t \rightarrow \infty} y(t)=\lim _{t \rightarrow \infty} y^{\prime}(t)=\lim _{t \rightarrow \infty} y^{\prime \prime}(t)=0
$$

provided

(a) (3.20) and (3.21) hold, or

(b) (3.20) and (3.26) hold. 
We conclude by discussing various classes of equations which satisfy the hypotheses of Theorem 3.3.

EXAMPLE 3.4. If $p(t) \equiv 0, q(t) \leqq 0, r(t)>0$, and if equation (1.1) is oscillatory, then it has two independent oscillatory solutions (Lemma 2.3) and (3.21) holds trivially so that any nonoscillatory solution satisfies (3.27). This is a result of Jones [15].

EXAMPLE 3.5. If $r(t)>0, q(t) \leqq 0$ and if there exists $M>0$ with $t p(t)-t^{2} q(t) \geqq-M$ and either

(i) $\quad \liminf _{t \rightarrow \infty} t^{3} r(t)>0$

or

(ii) $\liminf _{t \rightarrow \infty}\left(t p(t)-t^{2} q(t)\right)>2$,

then any nonoscillatory solution of (1.1) satisfies (3.27), if (1.1) is oscillatory. This follows from Lemma 2.3 and the proof of Theorem 3.2. (Note that the additional assumptions of Theorem 3.2 are not required.)

EXAMPLE 3.6. If $r(t)>0, q(t) \leqq 0$, if (3.20) holds, and if either

(i) $p(t) / t \leqq M, \lim \sup _{t \rightarrow \infty}\left(2 p^{2}-3 p^{\prime}+q\right) \leqq-\delta<0$ for some $M>0, \delta>0$, or

(ii) $t p(t) \leqq M, \lim \sup _{t \rightarrow \infty} t^{2}\left(2 p^{2}-3 p^{\prime}+q\right)<\frac{1}{4}$

and if (1.1) is oscillatory, then the hypotheses of Theorem 3.3 hold. To see this, note that condition (i) and (3.18) imply that (3.21) holds if $y(t)>0, y^{\prime}(t)<0, y^{\prime \prime}(t)>0, t \geqq T$ and $y(t) \rightarrow c>0$. Since (3.20) holds, if $y(t)>0, y^{\prime}(t)<0, y^{\prime \prime}(t)>0, t \geqq t_{0}$, it follows by (3.19) that

$$
\int_{t_{0}}^{\infty} t P(t) y^{\prime \prime}(t) d t<+\infty
$$

Hence, if $t>T>t_{0}$, since $\left(P(t) y^{\prime \prime}(t)\right)^{\prime}<0$, we have

$$
\int_{T}^{t} s P(s) y^{\prime \prime}(s) d s \geqq P(t) y^{\prime}(t) \int_{T}^{t} s d s \geqq P(t) y^{\prime \prime}(t)\left(t^{2}-T^{2}\right) / 2
$$

Therefore $t^{2} P(t) y^{\prime \prime}(t) \rightarrow 0$ which implies $t^{2} y^{\prime \prime}(t) \rightarrow 0$. Thus, condition (ii) implies that (3.26) holds if $y(t) \rightarrow c>0$.

EXAMPLE 3.7. If $r(t)>0, q(t) \leqq 0$ if '(3.20) holds, if

(i) $\left|\int t\left(2 p^{2}-3 p^{\prime}+q\right) d t\right|<+\infty$, and if (1.1) is oscillatory, then the hypotheses of Theorem 3.3 hold.

This time we use the fact that the second order linear equation $u^{\prime \prime}+\phi(t) u=0$ is nonoscillatory if 


$$
\left|\int^{\infty} t \phi(t) d t\right|<+\infty
$$

and the fact that if $y(t)>0, y^{\prime}(t)<0, y^{\prime \prime}(t)>0$ and $y(t) \rightarrow c>0$, then in equation (3.16) $M>\theta(t) \geqq \delta>0$ by (3.20) so that $\left|\int^{\infty} t \theta(t) h(t) d t\right|<+\infty$ by (3.19) and condition (i).

EXAMPLE 3.8. As an example for the case when $r(t)>0, q(t) \geqq 0$, we use a special case of a result of Gera ([18], Satz 2 and [7]), which states that (1.1) is oscillatory (in fact, has two oscillatory solutions) if $p \leqq 0$, $\int^{\infty} p d t>-\infty$, and $u^{\prime \prime}+p u^{\prime}+q u=0$ is disconjugate and $v^{\prime \prime}+$ $p v^{\prime}+(q+\lambda t r) v=0$ is oscillatory for some $0<\lambda<\frac{1}{2}$. (This holds, if, for example $\int^{\infty} t q(t) d t<+\infty, \int^{\infty} t^{\delta+1} r(t) d t=+\infty$ for some $0<\delta<1$. (See [11].) Therefore the conclusion of Theorem 3.3 will hold if, in addition,

(i) $\quad q-p^{\prime} \leqq 0, p^{\prime} \geqq 0$

or

(i) $\int^{\infty}\left(r-q^{\prime}+p^{\prime \prime}\right) d t=+\infty$

and

(ii) $2 p^{2}+q-3 p^{\prime} \leqq 0$.

The result of Gera implies that $y y^{\prime}<0$ for any nonoscillatory solution $y$ of (1.1) and conditions (i) or (i)' imply that $y^{\prime} y^{\prime \prime}<0$ eventually. Thus, (3.19), (3.20), and (3.21) hold if $y \rightarrow c>0$.

\section{REFERENCES}

1. J. H. Barrett, Oscillation theory of ordinary linear differential equations, Advances in Math., 3 (1969), 415-509.

2. L. Erbe, Disconjugacy conditions for the third order linear differential equation, Canad. Math. Bull., 12 (1969), 603-613.

3. B Boundary value problems for ordinary differential equations, Rocky Mountain J. Math., 1 (1971), 709-729.

4. G. J. Etgen and C. D. Shih, Disconjugacy and oscillation of third order differential equations with nonnegative coefficients, Proc. Amer. Math. Soc., 38 (1973), 577-582.

5 . - On the oscillation of certain third order linear differential equations, Proc. Amer. Math. Soc., 41 (1973), 151-155.

6. Conditions for the nonoscillation of third order differential equations with nonnegative coefficients, SIAM J. Math. Anal., 6 (1975), 1-8.

7. M. Gera, Über einige Eigenschaften der Lösungen der Gleichung $x^{\prime \prime \prime}+a(t) x^{\prime \prime}+b(t) x^{\prime}+c(t) x$ $=0, c(t) \geqq 0$, Mat. Cas., 24 (1974), 357-370.

8. — Bedingungen für die Existenz oszillatorischer Lösungen der Gleichung, $x^{\prime \prime \prime}+a(t) x^{\prime \prime}+$ $b(t) x^{\prime}+c(t) x=0, c(t) \geqq 0$, Mat. Cas., 25 (1975), 23-40.

9. T. G. Hallam, Asymptotic behavior of the solutions of an nth order nonhomogeneous ordinary differential equation, Trans. Amer. Math. Soc., 122 (1966), 177-194. 
10. M. Hanan, Oscillation criteria for third order differential equations, Pacific J. Math., 11 (1961), 919-944.

11. P. Hartman, Ordinary Differential Equations, Wiley, New York, 1964.

12. J. Heidel, Qualitative behavior of solutions of a third order nonlinear differential equation, Pacific J. Math., 27 (1968), 507-526.

13. L. K. Jackson, Subfunctions and second order ordinary differential inequalities, Advances in Math., 2 (1968), 307-363.

14. G. D. Jones, Properties of solutions of a class of third order differential equations, J. Math. Anal. Appl., 48 (1974), 165-169.

15. G. D. Jones, An asymptotic property of solutions of $y^{\prime \prime \prime}+p y^{\prime}+q y=0$, Pacific J. Math., 48 (1973), 135-138.

16. W. J. Kim, Oscillatory properties of linear third order differential equations, Proc. Amer. Math. Soc., 26 (1970), 286-293.

17. A. C. Lazer, The behavior of solutions of the differential equation $y^{\prime \prime \prime}+p(x) y^{\prime}+q(x) y=0$, Pacific J. Math., 17 (1966), 435-466.

18. C. A. Swanson, Comparison and Oscillation Theory of Linear Differential Equations, Academic Press, New York, 1968.

Received November 11, 1975. Research supported by National Research Council of Canada Grant A-7673.

The University of Alberta 



\section{PACIFIC JOURNAL OF MATHEMATICS}

\section{EDITORS}

RICHARD ARENS (Managing Editor)

University of California

Los Angeles, California 90024

\author{
R. A. Beaumont \\ University of Washington \\ Seattle, Washington 98105
}

\section{J. DugunduI}

Department of Mathematics University of Southern California Los Angeles, California 90007

D. Gilbarg and J. Milgram

Stanford University

Stanford, California 94305

\section{ASSOCIATE EDITORS}

E. F. BECKENBACH
B. H. NeumanN

F. Wolp
K. YoshidA

\section{SUPPORTING INSTITUTIONS}

UNIVERSITY OF BRITISH COLUMBIA

CALIFORNIA INSTITUTE OF TECHNOLOGY

UNIVERSITY OF CALIFORNIA

MONTANA STATE UNIVERSITY

UNIVERSITY OF NEVADA

NEW MEXICO STATE UNIVERSITY

OREGON STATE UNIVERSITY

UNIVERSITY OF OREGON

OSAKA UNIVERSITY

\author{
UNIVERSITY OF SOUTHERN CALIFORNIA \\ STANFORD UNIVERSITY \\ UNIVERSITY OF HAWAII \\ UNIVERSITY OF TOKYO \\ UNIVERSITY OF UTAH \\ WASHINGTON STATE UNIVERSITY \\ UNIVERSITY OF WASHINGTON \\ AMERICAN MATHEMATICAL SOCIETY
}

The Supporting Institutions listed above contribute to the cost of publication of this Journal, but they are not owners or publishers and have no responsibility for its contents or policies.

Mathematical papers intended for publication in the Pacific Journal of Mathematics should be in typed form or offset-reproduced (not dittoed). double spaced with large margins. Underline Greek letters in red, German in green, and script in blue. The first paragraph or two must be capable of being used separately as a synopsis of the entire paper. Items of the biblography should not be cited there unless absolutely necessary, in which case they must be identified by author and Journal, rather than by item number. Manuscripts, in duplicate, may be sent to any one of the four editors. Please classify according to the scheme of Math. Reviews, Index to Vol. 39. All other communications should be addressed to the managing editor, or Elaine Barth, University of California, Los Angeles, California, 90024.

100 reprints are provided free for each article, only if page charges have been substantially paid. Additional copies may be obtained at cost in multiples of 50 .

The Pacific Journal of Mathematics is issued monthly as of January 1966. Regular subscription rate: $\$ 72.00$ a year (6 Vols., 12 issues). Special rate: $\$ 36.00$ a year to individual members of supporting institutions.

Subscriptions, orders for back numbers, and changes of address should be sent to Pacific Journal of Mathematics, 103 Highland Boulevard, Berkeley, California, 94708.

PUBLISHED BY PACIFIC JOURNAL OF MATHEMATICS, A NON-PROFIT CORPORATION Printed at Jerusalem Academic Press, POB 2390, Jerusalem, Israel.

Copyright (C) 1976 Pacific Journal of Mathematics All Rights Reserved 


\section{Pacific Journal of Mathematics}

\section{Vol. 64, No. $2 \quad$ June, 1976}

Richard Fairbanks Arnold and A. P. Morse, Plus and times............. 297

Edwin Ogilvie Buchman and F. A. Valentine, External visibility ......... 333

R. A. Czerwinski, Bonded quadratic division algebras.............. 341

William Richard Emerson, Averaging strongly subadditive set functions in unimodular amenable groups. II .........................

Lynn Harry Erbe, Existence of oscillatory solutions and asymptotic behavior for a class of third order linear differential equations ............. 369

Kenneth R. Goodearl, Power-cancellation of groups and modules........ 387

J. C. Hankins and Roy Martin Rakestraw, The extremal structure of locally compact convex sets ...................................

Burrell Washington Helton, The solution of a Stieltjes-Volterra integral

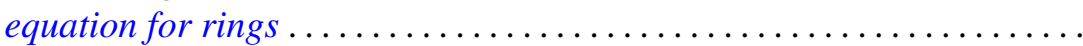

Frank Kwang-Ming Hwang and Shen Lin, Construction of 2-balanced

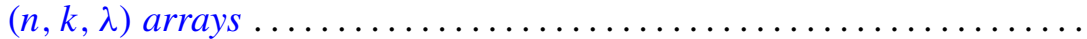

Wei-Eihn Kuan, Some results on normality of a graded ring ... 455

Dieter Landers and Lothar Rogge, Relations between convergence of series and convergence of sequences ......................... 465

Lawrence Louis Larmore and Robert David Rigdon, Enumerating immersions and embeddings of projective spaces ................

Douglas C. McMahon, On the role of an abelian phase group in relativized problems in topological dynamics..................

Robert Wilmer Miller, Finitely generated projective modules and TTF classes...

Yashaswini Deval Mittal, A class of isotropic covariance functions ...

Anthony G. Mucci, Another martingale convergence theorem ...

Joan Kathryn Plastiras, Quasitriangular operator algebras ...

John Robert Quine, Jr., The geometry of $p\left(S^{1}\right) \ldots \ldots \ldots$. 